Purdue University

Purdue e-Pubs

CTRC Research Publications

Cooling Technologies Research Center

2015

Effect of Particle Size on Surface-Coating Enhancement of Pool Boiling Heat Transfer

S. Sarangi

Purdue University

J.A. Weibel

Purdue University, jaweibel@purdue.edu

S V. Garimella

Purdue University, sureshg@purdue.edu

Follow this and additional works at: http://docs.lib.purdue.edu/coolingpubs

Sarangi, S.; Weibel, J. A.; and Garimella, S V., "Effect of Particle Size on Surface-Coating Enhancement of Pool Boiling Heat Transfer" (2015). CTRC Research Publications. Paper 250.

http://dx.doi.org/http://dx.doi.org/10.1016/j.ijheatmasstransfer.2014.09.052

This document has been made available through Purdue e-Pubs, a service of the Purdue University Libraries. Please contact epubs@purdue.edu for additional information. 


\title{
Effect of particle size on surface-coating enhancement of pool boiling heat transfer
}

\author{
Suchismita Sarangi, Justin A. Weibel and Suresh V. Garimella* \\ School of Mechanical Engineering and Birck Nanotechnology Center \\ Purdue University, 585 Purdue Mall, West Lafayette, IN 47907 USA
}

\begin{abstract}
The enhancement of pool boiling heat transfer by copper-particle surface coatings is experimentally investigated, using the wetting dielectric fluid FC-72. In one technique, loose copper particles are placed on a heated copper surface to provide additional vapor nucleation sites in the cavities formed at particlesurface and particle-particle contact points, thereby enhancing boiling performance over a polished surface. This 'free-particle' technique is benchmarked against the more traditional technique of sintering a fixed layer of copper particles to the surface to enhance boiling heat transfer performance. The effect of particle size on the heat transfer performance is studied for particle diameters ranging from $45 \mu \mathrm{m}$ to 1000 $\mu \mathrm{m}$ at a constant coating layer thickness-to-particle diameter ratio of approximately 4 . The parametric trends in the boiling curve and the critical heat flux are compared between the two techniques, and the dominant boiling mechanisms influencing these trends are compared and contrasted. High-speed visualizations are performed to qualitatively assess the boiling patterns and bubble departure size/distribution, and thus corroborate the trends observed in the boiling curves. The measured wall superheat is significantly lower with a sintered coating compared to the free-particle layer for any given particle size and heat flux. Performance trends with respect to particle size, however, are remarkably similar for both enhancement techniques, and an optimum particle size of $\sim 100 \mu \mathrm{m}$ is identified for both free particles and sintered coatings. The free-particle technique is shown to offer a straightforward method to screen the boiling enhancement trends expected from different particulate layer compositions that are intended to be subsequently fabricated by sintering.
\end{abstract}

Keywords: pool boiling, porous, sintered, free particles, heat transfer enhancement, particle size

*Corresponding author: Tel. 7654945621 ; sureshg@purdue.edu 


$\begin{array}{ll}\text { Nomenclature } & \\ A & \text { area, } \mathrm{m}^{2} \\ c_{p} & \text { specific heat capacity, } \mathrm{J} / \mathrm{kg} \cdot \mathrm{K} \\ d & \text { particle diameter, } \mathrm{m} \\ h_{f g} & \text { latent heat, } \mathrm{kJ} / \mathrm{kg} \\ k & \text { thermal conductivity, } \mathrm{W} / \mathrm{m} \cdot \mathrm{K} \\ q^{\prime \prime} & \text { total wall heat flux, } \mathrm{kW} / \mathrm{m}^{2} \\ T & \text { temperature, }{ }^{\circ} \mathrm{C} \\ U & \text { uncertainty } \\ x & \text { distance from surface, } \mathrm{m} \\ \text { Greek symbols } & \\ \delta & \text { coating thickness, } \mathrm{m} \\ \mu & \text { dynamic viscosity, } \mathrm{kg} / \mathrm{m} \cdot \mathrm{s} \\ \rho & \text { density, } \mathrm{kg} / \mathrm{m}^{3} \\ \sigma & \text { surface tension, } \mathrm{N} / \mathrm{m} \\ \text { Subscripts } & \\ 1-8 & \text { thermocouple locations } \\ a, b & \text { outer thermocouple rakes } \\ \text { bath } & \text { calibration bath } \\ c & \text { central thermocouple } \\ \text { ice } & \text { total } \\ \text { tot } & \text { wall } \\ w & \end{array}$




\section{Introduction}

Immersion cooling using phase change heat transfer is highly effective in applications requiring highdensity heat removal due to its simplicity, heat dissipation efficiency, and scalability. The mechanisms by which heat is dissipated from a surface during pool boiling consist of natural convection from the heated surface to the fluid, bulk convection induced by bubble growth and detachment, and latent heat transferred from the liquid phase to vapor bubbles formed at the surface [1]. With the advent of modern, high-performance electronic and electromechanical systems that have high-energy-density electrified components, there is need for enhancement of these heat transfer mechanisms to facilitate bubble nucleation at lower superheat temperatures and increase the critical heat flux (CHF).

The rich variety of boiling heat transfer enhancement techniques that have been demonstrated in the literature attempt to either modify the surface morphology or alter the properties of the working fluid by addition of external agents. The use of suspended nanoparticles in fluids has been widely studied for boiling performance enhancement, but with conflicting conclusions as described by Barber et al. [2] . Some studies have found that seeding water with a small concentration of alumina, zirconia, or silica nanoparticles enhances the thermal conductivity of the fluid, while also altering the surface wettability by roughening, thereby nearly doubling CHF $[3,4]$; however, the boiling heat transfer coefficient was reduced due to the deposition of an insulating nanoparticulate layer. Other studies report CHF values nearly triple those with pure water when alumina nanoparticles were included [5], and up to $60 \%$ higher than for pure water when silica nanoparticles were introduced [6], but with negligible change in the heat transfer coefficient. Conversely, boiling of water with cationic surfactants was shown by Hestroni et al. [7] to enhance the heat transfer coefficient at low surfactant concentration, while decreasing it at higher concentrations. White et al. [8] studied boiling of water with zinc oxide nanoparticles to explain these contrasting characteristics. The heat transfer coefficient increased initially due to enhanced thermal properties of the nanofluid; however, after deposition of a nanoparticle layer that completely covered the surface at higher concentrations, the heat transfer coefficient was decreased due to the suppression of bubble nucleation and release from the surface by the suspended nanoparticles (as in $[3,4]$ ).

Boiling surface modification techniques can be classified into two categories: integral surface roughness or external surface coatings/attachments. Berenson [9] studied boiling of n-pentane from roughened surfaces of nickel, copper, and Inconel, and observed up to a $600 \%$ increase in heat transfer coefficient with roughened surfaces. Kang [10] investigated boiling performance of water from stainless steel tubes of varying diameters, lengths, orientations, and roughness $(15.1-60.9 \mathrm{~nm})$, and observed that the heat transfer coefficient increased with surface roughness for vertical tubes by up to $230 \%$. The effect of surface roughness $(0.027 \mu \mathrm{m}$ to $10 \mu \mathrm{m})$ on pool boiling heat transfer performance was studied by Jones et al. [11] for water and FC-77. For FC-77, an increase in surface roughness continually increased the 
heat transfer coefficient by up to $210 \%$ than a baseline polished surface, whereas for water, improvement was not monotonic beyond $1.08 \mu \mathrm{m}$. McHale and Garimella [12] performed a study of the quantitative bubble departure characteristics from smooth and rough aluminum surfaces $(0.03 \mu \mathrm{m}$ and $5.89 \mu \mathrm{m}$, respectively) by high-speed flow visualizations in FC-77. Bubble departure frequency and the number of active nucleation sites were higher for the rough surface than the polished surface. While roughening the surface to provide preferential nucleation sites is an easy surface treatment technique to implement for effective heat transfer enhancement, this technique does not provide repeatable and predictable results due to ageing effects $[9,10]$.

Enhancement of pool boiling heat transfer by the use of external coatings and attachments, such as sintered coatings and wire meshes, has also been extensively investigated. The change in local surface morphology, by the addition of external surface enhancements, increases the number of available nucleation sites, and thus enhances performance by reducing the incipient and nucleate boiling superheats. This has proven to be a highly effective and reliable means of enhancing the heat transfer coefficient and critical heat flux in pool boiling. You et al. [13] spray-coated layers of 0.3-3 $\mu \mathrm{m}$ alumina particles over a surface and studied the boiling heat transfer performance of FC-72. Compared to a smooth surface, the particle-coated surface decreased the incipience wall superheat by $\sim 44 \%$ and increased CHF by $\sim 36 \%$. In a subsequent study, O'Connor and You [14] painted a mixture of silver flakes and epoxy over an aluminum surface to form a coating with $1 \mu \mathrm{m}$ cavities; the incipience superheat was reduced by $\sim 85 \%$ and CHF was increased by $\sim 109 \%$. Parker and El-Genk $[15,16]$ studied nucleate boiling of HFE-7100 and FC-72, respectively, from porous graphite layers containing randomly interconnected microscale pores (60\% porosity). For saturated HFE-7100, the heat transfer coefficient from the porous graphite was observed to be $1700 \%$ higher than that of a smooth copper surface at $10 \mathrm{~K}$ superheat, with the enhancement decreasing to $\sim 60 \%$ at CHF [15]. For FC-72, the critical heat flux was observed to increase by $63 \%$ at a $48 \%$ reduced surface superheat [16]. Bergles and Chyu [17] experimentally investigated the boiling characteristics of porous metallic coatings and found an increase in heat transfer coefficient of up to $250 \%$ for water and $800 \%$ for R-113. The boiling incipience superheat was drastically reduced due to the presence of corner cavities where the particles are attached to the surface. The porous coatings provided predictable and repeatable performance [18], as opposed to the ageing effects observed for roughened surfaces [19].

Many studies have been performed to study the parametric effects of sintered coating particle size, porosity, and thickness on pool boiling performance. Sintered copper wire screens of varying thickness, porosity, and mesh size were investigated by $\mathrm{Li}$ and Peterson [20] to determine their effects on boiling performance. At low heat fluxes, the heat transfer coefficient increased with coating thickness, but an optimum layer thickness was observed at higher heat fluxes that yielded a maximum heat transfer 
coefficient; porous coatings with higher thermal conductivity were observed to have higher heat transfer coefficients. Furthermore, a decrease in pore size caused the boiling incipience superheat to decrease, and increased the heat transfer coefficient. Nishikawa et al. [21] studied the effects of refrigerant boiling from different sizes and thicknesses of copper and bronze sintered powders on copper tubes. The maximum heat transfer coefficient was obtained when the coating thickness was about 4 times that of the mean particle diameter $(\delta / d=4)$, with copper powder being more effective than bronze. Lu and Chang [22] studied the effect of thickness, particle size, porosity, pore size distribution, and fluid properties on boiling heat transfer from sintered porous beds. It was observed that an increase in porosity, decrease in coating thickness, or increase in particle size all enhanced the CHF. A maximum enhancement in heat transfer coefficient was observed at $\delta / d=2$; as $\delta / d$ was further increased up to 10 , the heat transfer coefficient was enhanced at low heat fluxes, but reduced at higher heat fluxes.

Several additional studies of the performance of sintered porous coatings have identified the existence of an optimum layer thickness. Webb [23] reported an optimum coating thickness-to-particle diameter ratio of 4 for boiling of refrigerants from sintered copper surfaces. Chien and Chang [24] found a minimum thermal resistance for sintered copper powder layers in boiling water at an optimum coating thickness-to-particle diameter ratio of 3.85. The prediction of the optimum coating thickness was studied by Chang and You [25], and compared against experiments for boiling of FC-72 from surfaces coated with diamond particles. Based on an analysis that assumed a transient superheated liquid boundary layer to be formed above each nucleation site between successive bubble departures [26], an optimum coating thickness equal to the superheated liquid layer thickness was predicted. Using this optimum thickness as a threshold, coatings were categorized into micro-porous (below optimum) and porous (above optimum) coatings for the purposes of developing theoretical models for each scenario. A conduction-based model formulated by Ranjan et al. [27] considered the porous structure as analogous to extended fins, and defined an optimum thickness as the point of diminishing returns on fin effectiveness with increasing thickness. The optimum coating thickness-to-particle diameter ratio was in the range of 4-5.

As distinct from the techniques discussed above, the placement of loose copper particles on a heated surface has been recently explored as a technique for pool boiling heat transfer enhancement by Kim et al. $[28,29]$. This free-particle technique utilizes copper particles that are not attached to the heated surface to provide additional nucleation sites during pool boiling. High-speed flow visualization revealed that preferential bubble nucleation sites were formed at the corner cavities between the free particles and the heated surface, similar to sintered surfaces, causing enhancement of pool boiling heat transfer coefficient [28]. The effects of particle size, number of particles, and fluid properties were studied. For boiling of water with a single layer of free particles, it was found that particle sizes of 3 to $6 \mathrm{~mm}$ provided the largest heat transfer coefficients; a mixture of $3 \mathrm{~mm}$ and $6 \mathrm{~mm}$ particles increased the heat transfer 
coefficient by $115 \%$ compared to that of a polished surface. The existence of an optimum particle size was explained by nucleation theory: while larger particle/pore sizes require lower superheat for bubble incipience, smaller particles localize superheating of the liquid near the substrate. For a low surface tension fluid, FC-72 [29], microscale particles provided the greatest enhancement in heat transfer coefficient and CHF, due to the smaller cavity size at which bubble departure occurs. Increasing the number of particles placed on the surface increased heat transfer coefficient due to a larger number of active nucleation sites, but an overly large number of particles reduced CHF due to hydraulic resistance to liquid replenishment at the surface. Free particles $10 \mu \mathrm{m}$ in diameter, with an effective coating layer thickness of $67 \mu \mathrm{m}$, enhanced the heat transfer coefficient by $76 \%$, and increased CHF by $10 \%$, compared to a polished surface.

The free-particle enhancement technique is easily implemented and can provide insight into the expected boiling performance of sintered coatings; however, experimental results are not available for pool boiling from free and fixed (sintered) particulate layers of identical composition and under identical testing conditions (e.g., fluid, surface finish/material, heater size/orientation/confinement), preventing a direct comparison. In the present work, the heat transfer enhancement (in terms of incipient wall superheat, heat transfer coefficient, and CHF) of both free particles and sintered powder coatings are experimentally explored under identical conditions. Informed by the known sensitivity to particle size, and the existence of an optimal coating thickness-to-particle diameter ratio, the heat transfer performance is studied for particle sizes ranging from $45 \mu \mathrm{m}-1000 \mu \mathrm{m}$ at a constant $\delta / d=4$. A qualitative assessment of the boiling patterns and bubble departure size distributions is presented via high-speed visualizations of the entire heated surface to corroborate the trends observed in the boiling curves. The parametric trends in the boiling curves are found to be similar for both free-particle and sintered-particle coatings, although the heat transfer coefficient magnitudes differ significantly. The heat transfer mechanisms causing these similarities in parametric trends, albeit with differences in absolute performance, are explained.

\section{Experimental setup and procedure}

\subsection{Experimental setup}

Figure 1 shows a schematic diagram and photograph of the pool boiling test facility. This setup is a modified version of the test facility used by Kim et al. [29] for pool boiling experiments. The chamber is constructed from four polycarbonate walls sealed flush together with RTV silicone that is cured under compression with screws. The chamber walls compress a PTFE gasket and $1.2 \mathrm{~mm}$-thick polycarbonate plate that seals to the heater assembly with the test surface centered in the middle of the chamber below. A polycarbonate cover plate is sealed to the top of the chamber walls by compressing another PTFE 
gasket, forming a $30.48 \mathrm{~mm} \times 30.48 \mathrm{~mm} \times 93.9 \mathrm{~mm}$ sealed chamber confining the working fluid on the heated surface. The transparent walls of the polycarbonate housing allow flow visualization using a highspeed camera (Fastcam Ultima APX, Photron) at frame rates ranging from $1000-4000 \mathrm{fps}$.

The heater assembly consists of the copper heater block embedded in an insulation casing. The copper block has a smooth $25.4 \mathrm{~mm} \times 25.4 \mathrm{~mm}$ top surface exposed to the working fluid. This surface finish is prepared using a consistent procedure of sanding with progressively finer diamond sanding sheets ( 9 microns, 3 microns, and 0.1 microns) followed by metal polishing (Simichrome, Happich). This procedure results in a mirror-finish surface with roughness $R_{R M S}=20 \mathrm{~nm}$, as measured by a non-contact 3D scanning white light interferometer (NewView 6200, Zygo Corp.). Eight 0.889 mm-diameter holes on the sides of the copper block allow insertion of T-type thermocouples for temperature measurements along 3 rakes, as shown in the inset in Figure 1 (c). The copper is heated by 12 cartridge heaters (100 $\mathrm{W} / 60 \mathrm{~V}$ ) inserted into holes in the bottom surface of the block. For assembly, the upper half of the copper block is inserted into a block of PEEK, a machinable, low thermal conductivity $(0.28 \mathrm{~W} / \mathrm{m} \cdot \mathrm{K})$ thermoplastic that can withstand temperatures up to $250{ }^{\circ} \mathrm{C}$. The polished surface protrudes above the upper PEEK surface, and aligns flush with the top surface of the polycarbonate plate. An alumina silicate ceramic casing is placed around the bottom half of the copper block as insulation that can withstand higher temperatures than the PEEK. The ceramic placed under the copper block has 12 aligned holes so as to allow the cartridge heaters to pass through into the copper. A lower PEEK casing shrouds the ceramic blocks to provide further insulation and to affix all of the components in place.

A chamfer in the PEEK block around the outer edges of the test surface creates a groove surrounding the test surface with the $1.2 \mathrm{~mm}$-thick polycarbonate plate sealed to the top of the PEEK block; this groove helps in sealing the seams in the heater assembly exposed to the fluid. As shown in Figure 1 (b), a layer of RTV silicone sealant is first carefully placed in the groove using a syringe, and is allowed to cure for 90 minutes in an oven at $75{ }^{\circ} \mathrm{C}$. After the silicone is cured, a layer of epoxy (E $5302 \mathrm{Hi} \mathrm{Temp}$, Epoxylite) is applied to fill in the remaining gap. The entire facility is placed in the oven at $80{ }^{\circ} \mathrm{C}$ for 20 hours to cure the epoxy layer. The RTV silicone prevents wicking of the epoxy into the gap between the test piece and insulation, easing removal of the test piece between successive tests. The high-viscosity paste epoxy is chosen as a sealant so that it does not seep into the pores of sintered powder test surfaces. The polycarbonate plate helps to form a smooth meniscus in the epoxy layer around the edge of the test surface, and prevents premature activation of nucleation sites at the edge prior to incipience of boiling on the surface itself.

Within the test chamber, a T-type thermocouple is sealed through the polycarbonate cover plate to measure the pool temperature during testing. A $3.175 \mathrm{~mm}$-diameter stainless steel condenser tube is wound in a coil in the vapor space. During testing, a chilled 50\%-50\% water-glycol mixture is cycled 
through the stainless steel tube at a flow rate of $0.51 / \mathrm{min}$ at $15^{\circ} \mathrm{C}$ using a chiller (ULT-80, Neslab) to condense vapor. A $6.35 \mathrm{~mm}$-diameter polyurethane tube connects the liquid pool to a vapor trap. The chiller flow rate and set-point temperature were selected to ensure that no working fluid collects in the vapor trap during the experiment (to prevent fluid loss from the chamber over time). The vapor trap is open to ambient so as to maintain the chamber at atmospheric pressure during testing.

\subsection{Fabrication of test surfaces}

Two different boiling enhancement techniques are investigated, viz., the free-particle technique and sintered powder coatings. Spherical air-atomized copper particles of various size ranges are obtained from Alfa Aesar (44-149 $\mu \mathrm{m}$ and 0.8-2 mm) and ACuPowder International (105-250 $\mu \mathrm{m}$ ). The particles are sieved into size ranges of 45-53 $\mu \mathrm{m}, 90-106 \mu \mathrm{m}, 180-212 \mu \mathrm{m}$, and 850-1000 $\mu \mathrm{m}$. The layer thicknessto-particle diameter ratio for free particles is fixed at $\delta / d=4.8$ (reduced to approximately $\delta / d=4$ after densification by sintering), which has been previously observed as optimum for boiling enhancement from sintered particle coatings [23, 27].

To prepare the samples, the particles are first cleaned by soaking in acetone followed by a methanol rinse. A high-accuracy electronic scale (Voyager, Ohaus) is used to measure the weight of the particles placed on the heated surface. To fabricate a sintered sample, loose copper powder is poured into a graphite mold and leveled off to the desired height with a straight edge. The copper substrate is then gently placed on top of the copper powder. The mold, with the copper substrate, is placed into a bell jar furnace that is evacuated down to $\sim 10^{-2}$ torr $(\sim 1.33 \mathrm{~Pa})$ over 4 hours using a mechanical pump, after which a diffusion pump is turned on to pull a high vacuum of $\sim 10^{-6}$ torr $\left(\sim 1.33 \times 10^{-4} \mathrm{~Pa}\right)$ over approximately 12 hours. The temperature is steadily ramped for 2.5 hours up to $950{ }^{\circ} \mathrm{C}$ and held at this temperature for 60 minutes (an extended time of 120 minutes was required for the $850-1000 \mu \mathrm{m}$ particle size sample) under vacuum conditions. The assembly is then allowed to cool gradually to room temperature under vacuum $\left(\sim 5 \times 10^{-5}\right.$ torr $)$ so as to avoid oxidation, and immediately placed in an airtight container until it is tested. Figure 2 shows photographs of the $180-212 \mu \mathrm{m}$ and $850-1000 \mu \mathrm{m}$ sintered particle coatings; the coating is uniform and not oxidized after sintering. After sintering, the sample is inspected under an optical microscope at multiple locations to ensure a uniform height.

The test matrix in Table 1 includes the particle size, weight, porosity, and layer thickness for each sample. The weight of the particles differs for free and sintered particles because the free particles cover a larger $30.48 \mathrm{~mm} \times 30.48 \mathrm{~mm}$ area that includes coverage of the outer epoxy layer, while the sintered particles only coat the $25.4 \mathrm{~mm} \times 25.4 \mathrm{~mm}$ copper block surface. The porosity of the free particles is estimated by measuring the volume occupied by a known weight of copper powder, using a graduated cylinder. For the sintered coatings, a known weight of particles is sintered, and the height is measured 
after sintering to obtain the volume of the coating. The porosity is calculated based on the volume occupied by the known weight of particles. Figure 3 shows a side view of the sintered particle coatings used for this estimate, and a top view of the free particle layer.

\subsection{Experimental procedure}

In order to perform a test, the pool is filled with $40 \mathrm{ml}$ of fluorinert liquid $\mathrm{FC}-72$, which has the following thermophysical properties: $T_{\text {sat }}=56^{\circ} \mathrm{C}, \rho=1594 \mathrm{~kg} / \mathrm{m}^{3}, \mu=4.3 \times 10^{-4} \mathrm{~kg} / \mathrm{m} \mathrm{s}$, $k=0.054 \mathrm{~W} / \mathrm{m} \cdot \mathrm{K}, h_{f g}=88 \mathrm{~kJ} / \mathrm{kg}, c_{p}=1101 \mathrm{~J} / \mathrm{kg} \mathrm{K}$, and $\sigma=0.010 \mathrm{~N} / \mathrm{m} \mathrm{[30].} \mathrm{The} \mathrm{working} \mathrm{fluid} \mathrm{is}$ aggressively boiled for 2 hours prior to beginning the experiment, so as to degas the fluid and cavities on the surface. For testing using free particles, the cover plate is removed briefly, and a pre-determined quantity of the desired copper particles is introduced into the test chamber with caution to avoid scratching the test surface. The cover plate is then sealed, and the heat flux is increased in steps to obtain the boiling curve using the cartridge heaters. The pre-determined increments were small $\left(3-4 \mathrm{~kW} / \mathrm{m}^{2}\right)$ at low heat fluxes until boiling incipience, followed by larger increments $\left(10-12 \mathrm{~kW} / \mathrm{m}^{2}\right)$ during nucleate boiling, and finally reduced again $\left(7-10 \mathrm{~kW} / \mathrm{m}^{2}\right)$ when approaching CHF. The input voltage is measured across all the heaters connected in parallel. The power supplied to the heater block is monitored using a $0.01 \Omega$ shunt resistor connected in series with the system. Thermocouple temperature data are logged using a data acquisition system (34970A, Agilent) at $3 \mathrm{~s}$ intervals. Steady-state conditions are assumed to have been reached when the change in temperature versus time is less than $0.02{ }^{\circ} \mathrm{C} / \mathrm{s}$ over 30 minutes. Once this steady-state criterion is satisfied, the temperature data collected over $120 \mathrm{~s}$ are time-averaged for subsequent post-processing of the actual surface heat flux and corresponding surface temperature, as described below.

To determine the heat flux and wall superheat, the temperature gradients along the three thermocouple rakes are first calculated. The temperature gradient for the central rake is calculated by linear regression of temperature measurements at junctions $j_{1}, j_{2}, j_{3}$ and $j_{4}$, and for the outer rakes by a temperature differential. The local wall temperatures are then calculated as follows:

$$
\left(T_{w}\right)_{a}=T_{7}+x_{7}\left(\frac{d T}{d x}\right)_{a} ; \quad\left(T_{w}\right)_{b}=T_{5}+x_{5}\left(\frac{d T}{d x}\right)_{b} ; \quad\left(T_{w}\right)_{c}=T_{1}+x_{1}\left(\frac{d T}{d x}\right)_{c}
$$

Here, $T_{i}$ denotes temperature at thermocouple location $j_{i}$ as shown in Figure 1 (c), and $x_{i}$ denotes the distance from the top surface at this thermocouple location. Assuming uniform heat transfer from the top surface of the heater block, the area-average surface temperature is calculated using the areas shown schematically in the top view in Figure 1 (c). 


$$
T_{w}=\frac{\left(T_{w}\right)_{a} A_{a}+\left(T_{w}\right)_{b} A_{b}+\left(T_{w}\right)_{c} A_{c}}{\left(A_{a}+A_{b}+A_{c}\right)}
$$

The area-averaged heat flux is calculated similarly as follows:

$$
q_{\text {tot }}^{\prime \prime}=-k \frac{\left(\frac{d T}{d x}\right)_{a} A_{a}+\left(\frac{d T}{d x}\right)_{b} A_{b}+\left(\frac{d T}{d x}\right)_{c} A_{c}}{\left(A_{a}+A_{b}+A_{c}\right)}
$$

\subsection{Uncertainty Analysis}

The reference temperature for all thermocouple measurements is maintained by a dry-block ice-point (TCR-III, Omega). A resistance temperature detector (RTD) is used to measure the actual block temperature throughout testing, which provides higher accuracy than the thermocouples. The thermocouples are calibrated over the range of operating temperatures $\left(40{ }^{\circ} \mathrm{C}\right.$ to $110{ }^{\circ} \mathrm{C}$ at intervals of 10 ${ }^{\circ} \mathrm{C}$ ) using a stable temperature bath (7103 Microbath, Fluke) that is also monitored using an RTD. A least-squares linear regression fit, offset from the NIST ITS-90 [31] higher-order polynomial T-type thermocouple standard calibration curve, was used to obtain a new calibration for the thermocouples, where any offset from $0{ }^{\circ} \mathrm{C}$ in the ice-point reference junction temperature is measured and accounted for. Uncertainties in the linear-fit parameters are obtain according to Brown et al. [32], and absolute temperature uncertainties are specified by the equipment manufacturers $\left(U_{T, i c e}= \pm 0.1{ }^{\circ} \mathrm{C}, U_{T, R T D}= \pm 0.1{ }^{\circ} \mathrm{C}\right.$ and $U_{T, \text { bath }}= \pm 0.05^{\circ} \mathrm{C}$ ).

The uncertainties in the measured quantities may be obtained by a standard deviation-based error propagation method. This results in an absolute temperature uncertainty of $\pm 0.23{ }^{\circ} \mathrm{C}$. For differential temperature measurements, on account of simultaneous calibration of all thermocouples, the reduced propagated uncertainty is $\pm 0.06{ }^{\circ} \mathrm{C}$ per the uncertainty in calibration slope, as described in [33]. At steady state, the temperature is averaged over 40 readings; since the thermocouple locations are fixed, the random uncertainty in the axial location is assumed to be zero, while the systematic uncertainty is taken as the maximum clearance between the thermocouple bead diameter and the diameter of the tapped holes in the copper block, $40 \mu \mathrm{m}$. The heat flux is obtained from a linear fit to the temperature rake data; the uncertainties in the linear fit by a least-squares regression are obtained as described in [32]. The respective area-averaged surface temperature and heat flux uncertainties are approximately $\pm 0.1^{\circ} \mathrm{C}$ and $\pm 4.5 \mathrm{~kW} / \mathrm{m}^{2}$ over the range of heat fluxes investigated.

\section{Results and discussion}




\subsection{Free-particle coating}

The mechanism by which heat transfer is enhanced upon the addition of free particles during pool boiling is by creation of surface cavity geometries that are favorable for vapor nucleation [28, 29], as with other fixed enhancement coatings. However, the interactions of the particles with the surrounding liquid and departing vapor are distinct. At the initiation of boiling, individual vapor bubbles are formed within the layer of stacked free particles, which coalesce to form stable vapor columns as the heat flux is increased gradually. The actively deformable particles are displaced by the release of trapped vapor from the surface [34]. Depending on the size of particles used, as the vapor bubbles are carried upward by buoyant forces, some particles may become temporarily suspended in the liquid. Larger particles quickly settle back into the bed, while smaller particles have a longer residence time in the fluid, giving the appearance of a more uniform suspension. It may be noted here that despite the chaotic motion of free particles during boiling, the temporal averages of the surface temperature and heat flux still reach repeatable steady-state values per the criteria established in Section 2.3.

The parametric effects of free-particle size on pool boiling performance are investigated with particle diameters ranging from $45 \mu \mathrm{m}$ to $1000 \mu \mathrm{m}$ and compared against the polished surface baseline case; layer thickness is maintained at a constant value of 4.8 particle diameters for all cases. The boiling curves obtained are shown in Figure 4. In comparison to the polished surface, the free particles are observed to generally enhance performance in terms of the heat transfer coefficient (i.e., wall superheat is reduced at a given heat flux). A trade-off is observed between the magnitude of nucleate boiling heat transfer coefficient enhancement at low heat fluxes and the rate of increase of heat transfer coefficient with increasing heat flux as the particle size is decreased from $850-1000 \mu \mathrm{m}$ to $45-53 \mu \mathrm{m}$. At low heat fluxes, larger particles create nucleation cavity geometries that allow for bubble incipience and departure at lower superheat with larger bubble diameter. As particle size decreases, the theoretical number of active nucleation sites over the same heated area increases; however, smaller particles are more easily drawn into suspension in the fluid, reducing the nucleation site density and heat transfer coefficient at the lowest heat fluxes following boiling incipience. Conversely, a decrease in particle size and dimensional coating thickness supports a higher CHF, as vapor clogging and resistance to liquid replenishment at the surface are reduced compared to the larger sizes. The trends observed in the boiling curves are a result of these counteracting mechanisms. Figure 5 provides additional visual evidence of these mechanisms using images taken from high-speed flow visualizations (2000 fps) of the particulate layer for the different free particle sizes with increasing heat flux, as described below. It may be noted that the CHF value reported in these graphs corresponds to the heat flux just prior to the onset of CHF, and hence represents a lower bound on CHF within the heat flux increment size. 
For the largest particle size $(850-1000 \mu \mathrm{m}$, Figure 5 (a)), the particles remain settled on the surface for the entire range of heat fluxes. Due to the consistent number of nucleation sites, the boiling curve slope is constant, and the heat transfer performance is enhanced relative to the polished surface up to 30 $\mathrm{kW} / \mathrm{m}^{2}$. As the heat flux increases, the vapor bubbles coalesce in the static layer, impeding vapor departure and ultimately causing a crossover with the polished baseline boiling curve and a commensurately reduced CHF.

For the next lower particle size $(180-212 \mu \mathrm{m}$, Figure $5(\mathrm{~b}))$, the layer is actively displaced during boiling and particles migrate along the surface due to the surrounding fluid flow patterns. Nucleate boiling performance is similar to the $850-1000 \mu \mathrm{m}$ particle size at low heat fluxes up to the point where the boiling curves intersect with the polished surface baseline. At this heat flux, where vapor clogging had caused CHF for the 850-1000 $\mu \mathrm{m}$ particles, the deformable 180-212 $\mu \mathrm{m}$ layer does not restrict vapor departure from the surface. At this intermediate particle size, the particles are too heavy to become easily entrained into the fluid, and instead tend to build up along the chamber side walls, exposing large areas of polished copper. Over the areas where the underlying polished surface is exposed, nucleation is suppressed, and the boiling curve follows the polished surface closely. This behavior is unique to the particle size range of 180-212 $\mu \mathrm{m}$; larger particles tend to form a uniform static layer and smaller particles are more uniformly redistributed over the surface when entrained into the fluid. Although the free particles are continuously redistributed across the surface during the experiment, the surface temperature is nearly constant with time once steady-state conditions are achieved.

As particle size decreases further to $90-106 \mu \mathrm{m}$, a trade-off is observed between lower incipience wall superheat at the onset of nucleate boiling and lower wall superheats at higher heat fluxes relative to the larger particle sizes. The onset of nucleate boiling occurs at a higher wall superheat $(9.5 \mathrm{~K}$ for $90-106 \mu \mathrm{m}$ particles compared to $6.8 \mathrm{~K}$ for 180-212 $\mu \mathrm{m}$ ), and the wall superheat remains larger than that of the 180$212 \mu \mathrm{m}$ particles for heat fluxes up to $25 \mathrm{~kW} / \mathrm{m}^{2}$, due to the smaller bubble departure diameter, as observed from Figure 5 (a-c). At higher heat fluxes the boiling curves cross, and enhanced heat transfer performance is measured for the $90-106 \mu \mathrm{m}$ free particles. At higher heat fluxes, when the vapor bubbles begin to coalesce, smaller particle sizes give rise to smaller coalesced bubbles. These bubbles have less difficulty in displacing - and departing from - the particulate layer, leading to lower wall superheat as compared to the larger particle sizes. The difference compared to larger particles starts at heat fluxes higher than $25 \mathrm{~kW} / \mathrm{m}^{2}$, as similarly observed for sintered coatings by Chang and You [25]. As the boiling process becomes more vigorous at these higher heat fluxes, visualization of the smaller 90-106 $\mu \mathrm{m}$ particles (Figure 5 (c)) shows that nucleation sites remain active and uniform over the surface due to intermittent settling of particles, whereas nucleation was non-uniform and vapor was forced to depart through thick particulate layers for the comparatively larger 180-212 $\mu \mathrm{m}$ particles. 
This trend continues as the particle size is further decreased to $45-53 \mu \mathrm{m}$. The nucleate boiling performance deteriorates further because the smallest particles are so easily entrained into the fluid that few remain on the surface to provide active nucleation sites. There is not a layer of particles continually covering and impeding liquid replenishment to the surface (Figure $5(\mathrm{~d})$ ); therefore, this smaller particle size sustains a much higher CHF of $161 \mathrm{~kW} / \mathrm{m}^{2}$. It may be noted here that the CHF reached by this smallest particle size considered is higher than that for the polished surface $\left(112 \mathrm{~kW} / \mathrm{m}^{2}\right)$. This may be attributed to alteration of the surface wettability or additional capillarity effects provided by some deposition of the small particles on the surface, as is observed in the case of nanofluids [35], or to some roughening of the surface due to erosion by the motion of the suspended particles.

In summary, free particles in the size range of 90-106 $\mu \mathrm{m}$ are observed to show the best nucleate boiling performance, with a $32 \%$ reduction in the surface superheat compared to the polished surface at $112 \mathrm{~kW} / \mathrm{m}^{2}$ (the flux at which the polished surface reaches CHF). Free particles in the diameter range of 45-53 $\mu$ m yield the maximum CHF $\left(161 \mathrm{~kW} / \mathrm{m}^{2}\right), 44 \%$ higher than that of a polished surface.

Comparison with previous studies on the free-particle enhancement technique using FC-72 [29] shows similar trends as observed in the present study, although quantitative differences are observed in the boiling curves due to the different coating thickness and particle size ranges considered in this study. As in the current study, the larger particles were reported to enhance the heat transfer coefficient compared to a polished surface at low heat fluxes, but with an accompanying reduction in CHF. While this occurred at a particle diameter range of $850-1000 \mu \mathrm{m}$ in the current study, premature CHF was not observed until much larger, millimeter-sized particles in [29] due to the smaller monolayer coating thicknesses used, with commensurately lower hydraulic resistance. In both studies, a significant improvement in heat transfer coefficients throughout the boiling curves was observed as compared to a polished surface once the free particle diameter was decreased to less than $\sim 150 \mu \mathrm{m}$, and critical heat flux enhancement was observed for free particles on the order of 10 s of microns in diameter (44\% for $45-53$ $\mu \mathrm{m}$ particles in the current study, $10 \%$ for $10 \mu \mathrm{m}$ particles in [29]).

\subsection{Sintered particle coating}

The parametric effects of sintered particle size on pool boiling enhancement are investigated with particle diameters ranging from $45 \mu \mathrm{m}$ to $1000 \mu \mathrm{m}$ as compared against the polished surface baseline case. The sintered coatings are prepared with a thickness of approximately 4 particle layers, as shown in Table 1. The boiling curves for the sintered surface are shown in Figure 6. All of the particle sizes investigated are observed to enhance performance compared to a polished surface, due to an increase in the number of active nucleation sites. Figure 7 provides visual evidence of the mechanisms affecting the 
parametric trends in the boiling curves using images taken from high-speed flow visualization at 2000 fps, as described below.

For the largest particle size $(850-1000 \mu \mathrm{m}$, Figure 7 (a)), the wall superheat at incipience as well as nucleate boiling over the entire range of heat fluxes are reduced significantly as compared to a polished surface (shown in Figure 4), due to the increased number of active nucleation sites formed by the porous surface; however, coalescence and clogging of vapor bubbles in the relatively thick layer hinders bubble departure, leading to reduced CHF. For the next smaller particle size (180-212 $\mu \mathrm{m}$, Figure 7 (b)), the heat transfer coefficient is enhanced, and CHF is increased. The enhancement in heat transfer coefficient is due to the larger number of nucleation sites available at any heat flux over the same area for the smaller particles. Since smaller particles have smaller coating thickness ( $\delta / d$ constant), they are able to support a higher CHF. As particle size decreases further to 90-106 $\mu \mathrm{m}$, (Figure 7 (c)), the heat transfer coefficient is further enhanced due to the larger number of nucleation sites; however, the CHF is reduced. A possible reasoning for this anomalous decrease in CHF may be due to a reduction in the effective heat transfer area having a more dominant effect than reduced hydraulic resistance with a reduction in coating thickness. This is a similar mechanism of CHF reduction as found in previous studies [36], wherein for a fixed particle size, a decrease in coating thickness was observed to cause a decrease in CHF, due to a reduction in effective heat transfer area. As the particle size reduces further $(45-53 \mu \mathrm{m}$, Figure 7 (d)), the trend of increasing CHF is restored, with the maximum CHF observed for the smallest particle size; and the heat transfer coefficient decreases. Although the available nucleation site density increases, the small pore sizes less favorable for bubble incipience reduce the number of active nucleation sites. It should be noted that the wall superheat values are very low $(<2 \mathrm{~K})$ for the sintered surfaces with particle sizes from 45 $212 \mu \mathrm{m}$, and hence the performance differences observed between these cases are small compared to the experimental uncertainty, and show less contrast than between cases for the free particles. The 90-106 $\mu \mathrm{m}$ particles show the maximum decrease in wall superheat compared to a polished surface at $\sim 72 \mathrm{~kW} / \mathrm{m}^{2}$ $(20.4 \mathrm{~K}$ to $1.3 \mathrm{~K})$.

Several studies in the literature have similarly shown the effect of particle size on boiling heat transfer enhancement with sintered coatings. Chang and You [25] investigated boiling of FC-72 from a nonconductive epoxy-based porous surface, where the coating thickness increased with particle size. The heat transfer coefficient increased with an increase in particle size from $2 \mu \mathrm{m}$ to $20 \mu \mathrm{m}$, but decreased with further increases in particle size. The coating thickness for this optimum $20 \mu \mathrm{m}$ particle case corresponded to the liquid layer thickness that was predicted to become superheated between successive bubble departures; any further increase in thickness added hydraulic resistance without any fin-effect benefit. In the present study, a similar trade-off in heat transfer coefficient with particle diameter is observed; however, the optimum particle size of 90-106 $\mu \mathrm{m}$ (at a layer thickness of $402 \mu \mathrm{m}$ ) is larger for 
the sintered copper particles. A similar increase compared to the predicted value was also observed by Scurlock [37], where the optimum coating thickness was $250 \mu \mathrm{m}$ compared to the calculated superheated liquid layer thickness of $100 \mu \mathrm{m}$ for liquid nitrogen. Chang and You [25] attributed this increased optimum thickness to the higher thermal conductivity of the plasma-sprayed aluminum particle coating. Following a similar analysis as proposed by Hsu [26], the superheated liquid layer thickness for FC-72 was estimated to be $100 \mu \mathrm{m}$ (as in [25]); however, due to the high thermal conductivity of the current sintered copper coating as compared to the epoxy-based porous coating in [25], the observed optimum coating thickness was higher for the present coating $(\sim 400 \mu \mathrm{m})$.

Figure 8 shows a direct comparison between the boiling curves obtained for the free-particle and sintered-coating enhancement techniques. It is observed that sintered surfaces significantly outperform the free particles at any given particle size, even for the cases $(850-1000 \mu \mathrm{m})$ where the free particles exhibit minimal particle motion during boiling. This can only be attributed to the primary morphological difference between the structures, which is the sintered neck formed between particles. This improves the conductivity of the sintered particles, allowing the layer to enhance the effective heat transfer area (whereas the point-contact between spherical free particles limits the conductivity of the free-particle layer). Also, the fixed structure may provide additional capillary wicking of liquid to the surface. While the free particles actively deform during boiling, the sintered particles provide a stable capillary column that provides a continuous path for replenishment of bulk liquid to the heated surface. For smaller particles (approximately less that $200 \mu \mathrm{m}$ ), the free particles become suspended in the fluid during boiling, which reduces the temporal average number of particles in contact with the surface at all times and thereby decreases the number of active nucleation sites. While the absolute boiling performance of both techniques shows significant differences, the trends observed with particle size are remarkably similar. For both techniques, the maximum heat transfer coefficient is observed at a particle size of 90$106 \mu \mathrm{m}$, and the maximum CHF is attained for $45-53 \mu \mathrm{m}$-diameter particles.

\section{Conclusions}

Free particles and sintered particle coatings are explored for enhancement of pool boiling heat transfer of FC-72 from a heated copper surface, and the effects of particle size are studied for a nearly constant coating layer thickness-to-particle diameter ratio ranging from 4 to 5 . With free particles, the 90 $106 \mu \mathrm{m}$ particles exhibit the best boiling heat transfer at higher heat fluxes, with a $32 \%$ reduction in the surface superheat compared to the polished surface at $112 \mathrm{~kW} / \mathrm{m}^{2}$; however, the maximum critical heat flux $\left(161 \mathrm{~kW} / \mathrm{m}^{2}\right)$ is attained with the $45-53 \mu \mathrm{m}$ particles, $44 \%$ higher than that for a polished surface. While free particles provide an actively deformable layer that allows the escape of trapped vapor from the surface (and thereby does not diminish CHF for most particle sizes), entrainment of free particles into the 
liquid reduces the number of active nucleation sites available for pool boiling at any given time instant. Hence, the fixed sintered particles exhibit significantly higher heat transfer enhancement over a polished surface as compared to free particles of similar size and layer thickness. Nonetheless, the trends observed with particle size are similar between the free-particle and sintered-coating techniques. The bestperforming sintered coating, in terms of heat transfer coefficient, has the same 90-106 $\mu \mathrm{m}$ particle range as the free particles, and provides a 95\% decrease in wall superheat, albeit at a critical heat flux that is $33 \%$ lower than that for the polished surface. The $45-53 \mu \mathrm{m}$ sintered coating has a CHF approximately the same as that of the polished surface. As the free-particle technique is significantly easier to implement, it may serve as an efficient gauge of expected parametric trends in boiling performance from sintered surfaces.

\section{Acknowledgements}

Funding for this work from the Cooling Technologies Research Center, an NSF I/UCRC at Purdue University, is gratefully acknowledged. The authors also thank Steve Titolo at Thermophysical Properties Research Laboratory Inc. (TPRL) for assistance with fabrication of the sintered surfaces. 


\section{References}

[1] C. Y. Han and P. Griffith, The mechanism of heat transfer in nucleate pool boiling-Part I, International Journal of Heat and Mass Transfer 8 (6) (1965) 887-904.

[2] J. Barber, D. Brutin, and L. Tadrist, A review on boiling heat transfer enhancement with nanofluids, Nanoscale Research Letters 6 (1) (2011) 280.

[3] S. J. Kim, I. C. Bang, J. Buongiorno, and L. W. Hu, Effects of nanoparticle deposition on surface wettability influencing boiling heat transfer in nanofluids, Applied Physics Letters 89 (15) (2006) 3107.

[4] S. J. Kim, I. C. Bang, J. Buongiorno, and L. W. Hu, Surface wettability change during pool boiling of nanofluids and its effect on critical heat flux, International Journal of Heat and Mass Transfer 50 (19-20) (2007) 4105-4116.

[5] S. M. You, J. H. Kim, and K. H. Kim, Effect of nanoparticles on critical heat flux of water in pool boiling heat transfer, Applied Physics Letters 83 (16) (2003) 3374.

[6] P. Vassallo, R. Kumar, and S. D'Amico, Pool boiling heat transfer experiments in silica-water nano-fluids, International Journal of Heat and Mass Transfer 47 (2) (2004) 407-411.

[7] G. Hetsroni, J. Zakin, Z. Lin, A. Mosyak, E. Pancallo, and R. Rozenblit, The effect of surfactants on bubble growth, wall thermal patterns and heat transfer in pool boiling, International Journal of Heat and Mass Transfer 44 (2) (2000) 485-497.

[8] S. B. White, A. J. Shih, and K. P. Pipe, Effects of nanoparticle layering on nanofluid and base fluid pool boiling heat transfer from a horizontal surface under atmospheric pressure, Journal of Applied Physics 107 (11) (2010) 4302.

[9] P. J. Berenson, Experiments on pool-boiling heat transfer, International Journal of Heat and Mass Transfer 5 (10) (1962) 985-999.

[10] M. G. Kang, Effect of surface roughness on pool boiling heat transfer, International Journal of Heat and Mass Transfer 43 (22) (2000) 4073-4085.

[11] B. J. Jones, J. P. McHale, and S. V. Garimella, The influence of surface roughness on nucleate pool boiling heat transfer, Journal of Heat Transfer 131 (12) (2009) 1009.

[12] J. P. McHale and S. V. Garimella, Bubble nucleation characteristics in pool boiling of a wetting liquid on smooth and rough surfaces, International Journal of Multiphase Flow 36 (4) (2010) 249260.

[13] S. M. You, T. W. Simon, and A. Bar-Cohen, A technique for enhancing boiling heat transfer with application to cooling of electronic equipment, IEEE Transactions on Components, Hybrids, and Manufacturing Technology 15 (5) (1992) 823-831.

[14] J. P. O'Connor and S. M. You, A painting technique to enhance pool boiling heat transfer in saturated FC-72, Journal of Heat Transfer 117 (2) (1995) 387.

[15] M. S. El-Genk and J. L. Parker, Enhanced boiling of HFE-7100 dielectric liquid on porous graphite, Energy Conversion and Management 46 (15-16) (2005) 2455-2481.

[16] J. L. Parker and M. S. El-Genk, Enhanced saturation and subcooled boiling of FC-72 dielectric liquid, International Journal of Heat and Mass Transfer 48 (18) (2005) 3736-3752.

[17] A. E. Bergles and M. C. Chyu, Characteristics of nucleate pool boiling from porous metallic coatings, Journal of Heat Transfer 104 (2) (1982) 270.

[18] V. I. Borzenko and S. P. Malyshenko, Mechanisms of phase exchange under conditions of boiling on surfaces with porous coatings, High Temperature 39 (5) (2001) 714-721.

[19] I. H. Chaudhri and I. R. McDougall, Ageing studies in nucleate pool boiling of isopropyl acetate and perchloroethylene, International Journal of Heat and Mass Transfer 12 (6) (1969) 681-688.

[20] C. Li and G. P. Peterson, Parametric study of pool boiling on horizontal highly conductive microporous coated surfaces, Journal of Heat Transfer 129 (11) (2007) 1465. 
[21] K. Nishikawa, T. Ito, and K. Tanaka, Enhanced heat transfer by nucleate boiling on a sintered metal layer, Heat Transfer - Japanese Research 8 (2) (1979) 65-81.

[22] S. M. Lu and R. H. Chang, Pool boiling from a surface with a porous layer, AIChE Journal 33 (11) (1987) 1813-1828.

[23] R. L. Webb, Nucleate boiling on porous coated surfaces, Heat Transfer Engineering 4 (3-4) (1981) 71-82.

[24] L. Chien and C. C. Chang, Experimental study of evaporation resistance on porous surfaces in flat heat pipes, Proceedings of 8th IEEE Intersociety Conference on Thermal and Thermomechanical Phenomena in Electronic Systems (ITherm), San Diego, CA, 2002 236-242.

[25] J. Y. Chang and S. M. You, Boiling heat transfer phenomena from microporous and porous surfaces in saturated FC-72, International Journal of Heat and Mass Transfer 40 (18) (1997) 4437-4447.

[26] Y. Y. Hsu, On the size range of active nucleation cavities on a heating surface, Journal of Heat Transfer, 84 (3) 1962207.

[27] R. Ranjan, J. Y. Murthy, and S. V. Garimella, Bubble dynamics during capillary-fed nucleate boiling in porous media, Proceedings of 13th IEEE Intersociety Conference on Thermal and Thermomechanical Phenomena in Electronic Systems (ITherm), San Diego, CA, 2012 1114-1126.

[28] T.Y. Kim and S.V. Garimella, Investigation of boiling heat transfer in water using a free-particlesbased enhancement technique, International Journal of Heat and Mass Transfer 71 (2014) 818-828.

[29] T.Y. Kim, J.W. Weibel, and S.V. Garimella, A free-particles-based technique for boiling heat transfer enhancement in a wetting liquid, International Journal of Heat and Mass Transfer 71 (2014) 808-817.

[30] 3M Corporation, Fluorinert Electronic Liquid FC-72 Product Information 98-0212-2308-0 (HB), Specialty Materials Division, 2000.

[31] G. W. Burns, M. G. Scroger, G. F. Strouse, M. C. Croakin and W. F. Guthrie, NIST Monograph 175, Temperature-Electromotive Force Reference Functions and Tables for the Letter-Designated Thermocouple Types Based on the ITS-90, 1993.

[32] K. Brown, H. Coleman, and W. Steele, Estimating uncertainty intervals for linear regression, Proceedings of the 33rd Aerospace Science Meeting and Exhibit, Reno, NV, 1995.

[33] J. Ospina and E. Canuto, Uncertainty on differential measurements and its reduction using the calibration by comparison method, Metrologia 45 (4) (2008) 389-394.

[34] J. A. Weibel, S. Sarangi and S. V. Garimella, Pool Boiling Heat Transfer From Deformable Particulate Beds, Journal of Heat Transfer 135 (8) 2013080908.

[35] H. D. Kim and M. H. Kim, Effect of nanoparticle deposition on capillary wicking that influences the critical heat flux in nanofluids, Applied Physics Letters 91 (1) (2007) 4104.

[36] C. Li and G. P. Peterson, Experimental studies on CHF of pool boiling on horizontal conductive micro porous coated surfaces, AIP Conference Proceedings, 969 (1) 2008 12-20.

[37] R. G. Scurlock, Enhanced boiling heat transfer surfaces, Cryogenics 35 (4) (1995) 233-237. 


\section{List of Tables}

Table 1. Test matrix showing weight, thickness, and porosity of the free and sintered particle layers investigated at each particle size.

\section{List of Figures}

Figure 1. Schematic diagram of test facility with insets showing (a) a photograph of the test chamber, (b) a magnified diagram of the sealed seam around the outer edge of the copper test surface, and (c) the schematic top and side views of the copper block showing thermocouple locations and surface area designations (dimensions in $\mathrm{mm}$ ).

Figure 2. Photographs of the 180-212 $\mu \mathrm{m}$ and $850-1000 \mu \mathrm{m}$ diameter sintered particle coatings from top (left) and side (right) views.

Figure 3. Side view of the sintered coatings at $20 \times$ magnification (top row), and top view of the free particle layer at $5 \times$ magnification (bottom row), for various particles sizes from $45 \mu \mathrm{m}$ to $212 \mu \mathrm{m}$.

Figure 4. Boiling curves of area-averaged heat flux $\left(q^{\prime \prime}\right)$ versus wall superheat $(\Delta T)$ for a polished surface baseline compared against enhancement using free spherical copper particles $45 \mu \mathrm{m}$ to $1000 \mu \mathrm{m}$ in diameter $(\delta / d=4.8$; porosity $=40-45 \%)$. Critical heat flux is indicated with a horizontal arrow.

Figure 5. Images taken from high-speed visualization at $2000 \mathrm{fps}$ for (a) 850-1000 $\mu \mathrm{m}$, (b) 180-212 $\mu \mathrm{m}$, (c) $90-106 \mu \mathrm{m}$, and (d) $45-53 \mu \mathrm{m}$ free particle diameters at similar heat fluxes throughout the boiling curve (see Supplementary Video Data).

Figure 6. Boiling curves of area-averaged heat flux $\left(q^{\prime \prime}\right)$ versus wall superheat $(\Delta T)$ for surfaces with sintered spherical copper particles $45 \mu \mathrm{m}$ to $1000 \mu \mathrm{m}$ in diameter $(\delta / d \approx 4$ after sintering; porosity $=28$ $40 \%$ ). Critical heat flux is indicated with a horizontal arrow.

Figure 7. Images taken from high-speed visualization at $2000 \mathrm{fps}$ for (a) $850-1000 \mu \mathrm{m}$, (b) $180-212 \mu \mathrm{m}$, (c) $90-106 \mu \mathrm{m}$, and (d) $45-53 \mu \mathrm{m}$ sintered particle diameters at similar heat fluxes throughout the boiling curve (see Supplementary Video Data).

Figure 8. Comparison of trends in boiling curves of area-averaged heat flux $\left(q^{\prime \prime}\right)$ versus wall superheat $(\Delta T)$ for free and sintered particles with diameters ranging from $45 \mu \mathrm{m}$ to $1000 \mu \mathrm{m}$. 
Table 1. Test matrix showing weight, thickness, and porosity of the free and sintered particle layers investigated at each particle size.

\begin{tabular}{c|ccc|ccc}
\hline \multirow{2}{*}{$\begin{array}{c}\text { Particle size } \\
{[\mu \mathrm{m}]}\end{array}$} & \multicolumn{3}{|c|}{ Free particles } & \multicolumn{3}{c}{ Sintered particles } \\
\cline { 2 - 7 } & $\begin{array}{c}\text { Weight } \\
{[\mathrm{g}]}\end{array}$ & $\delta / d$ & $\begin{array}{c}\text { Porosity } \\
{[\%]}\end{array}$ & $\begin{array}{c}\text { Weight } \\
{[\mathrm{g}]}\end{array}$ & $\delta / d$ & $\begin{array}{c}\text { Porosity } \\
{[\%]}\end{array}$ \\
\hline $850-1000$ & 22.44 & 4.8 & $40.2 \pm 0.5$ & 15.03 & 4.2 & $32.9 \pm 0.5$ \\
\hline $180-212$ & 4.47 & 4.8 & $39.9 \pm 0.4$ & 3.03 & 4.2 & $36.3 \pm 1.5$ \\
\hline $90-106$ & 2.41 & 4.8 & $43.1 \pm 0.5$ & 1.68 & 4.1 & $27.3 \pm 1.5$ \\
\hline $45-53$ & 1.18 & 4.8 & $44.4 \pm 0.5$ & 0.84 & 4.1 & $27.3 \pm 3.0$ \\
\hline
\end{tabular}



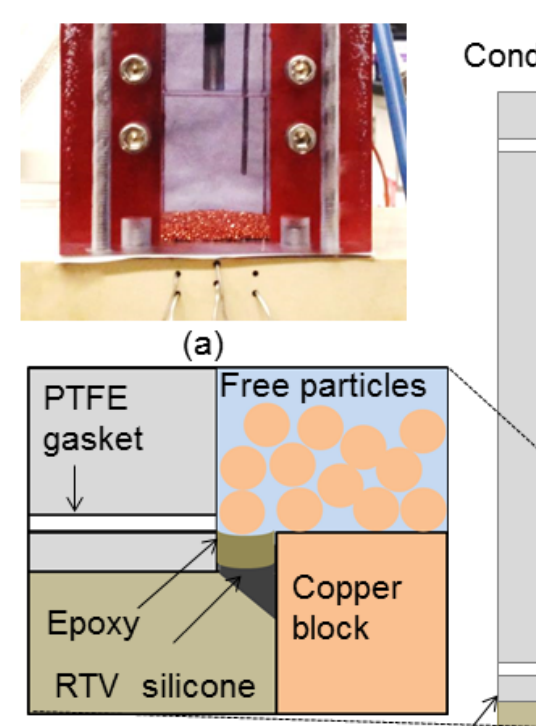

(b)
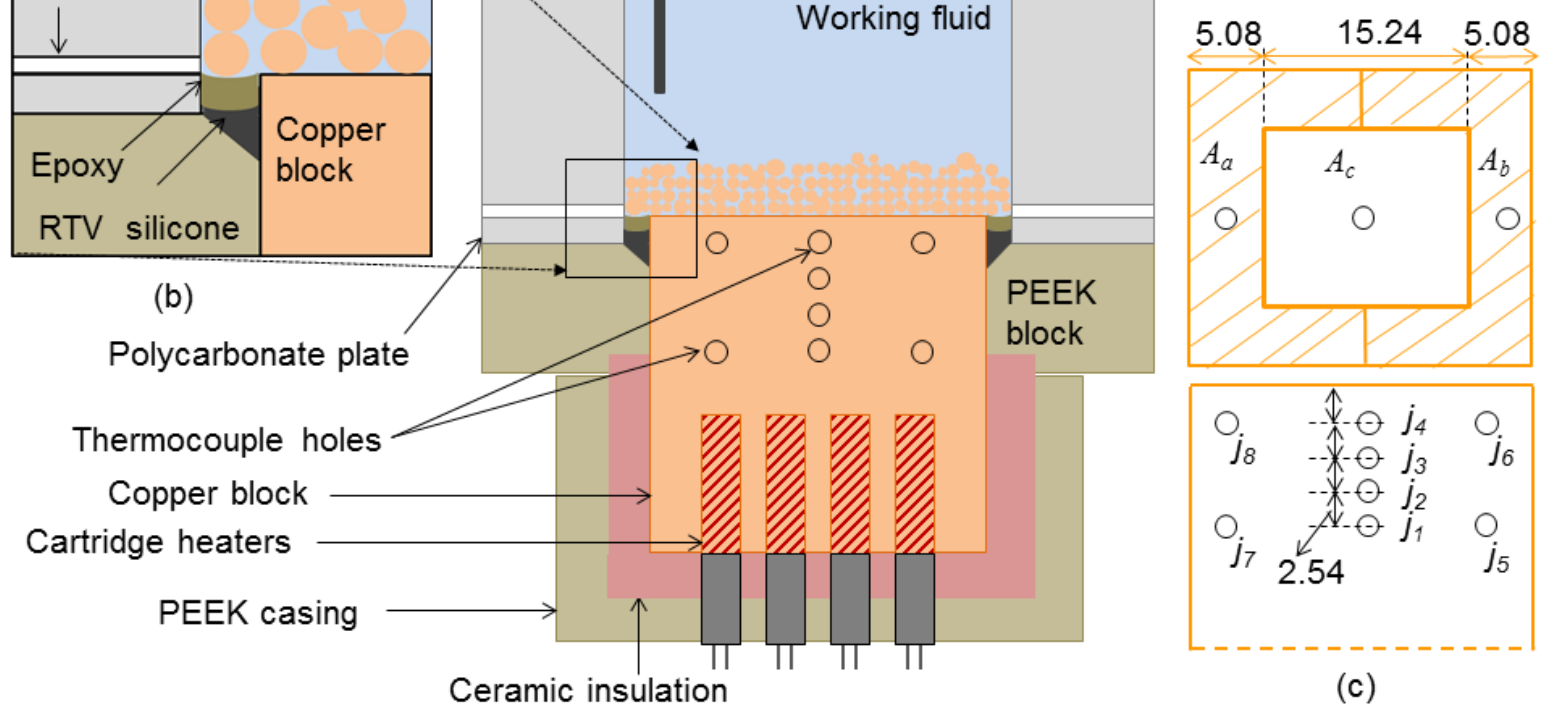

(c)

Figure 1. Schematic diagram of test facility with insets showing (a) a photograph of the test chamber, (b) a magnified diagram of the sealed seam around the outer edge of the copper test surface, and (c) the schematic top and side views of the copper block showing thermocouple locations and surface area designations (dimensions in $\mathrm{mm}$ ). 

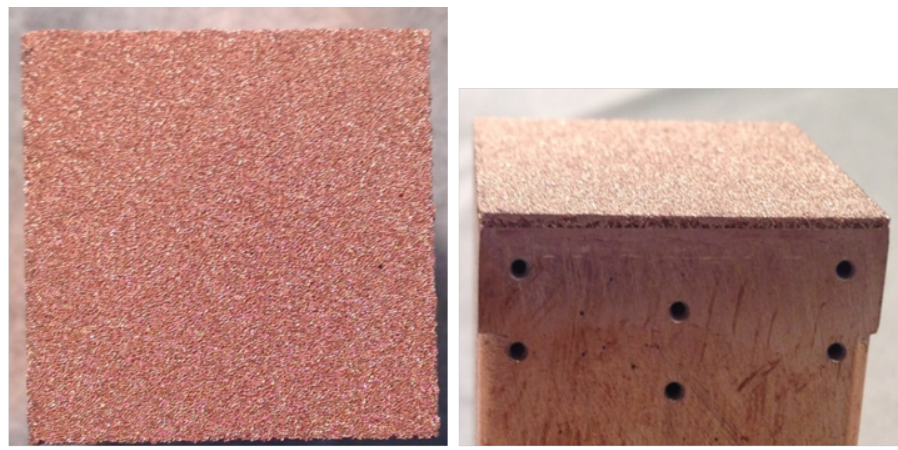

$180-212 \mu \mathrm{m}$

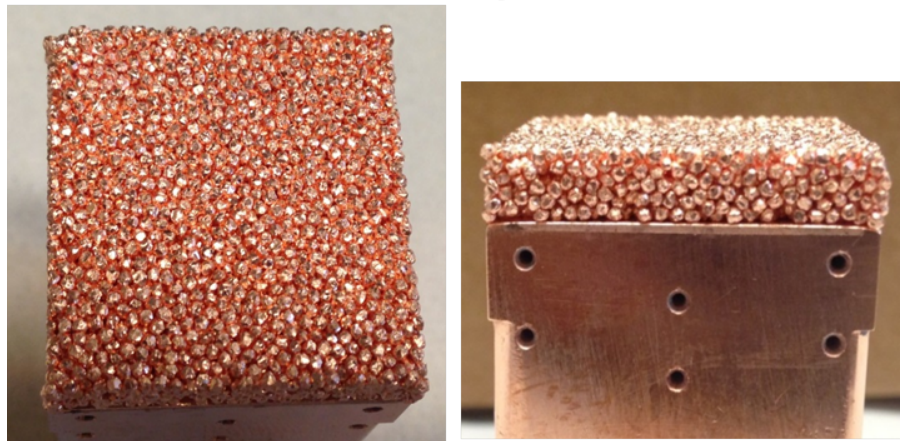

$850-1000 \mu \mathrm{m}$

Figure 2. Photographs of the 180-212 $\mu \mathrm{m}$ and $850-1000 \mu \mathrm{m}$ diameter sintered particle coatings from top (left) and side (right) views. 

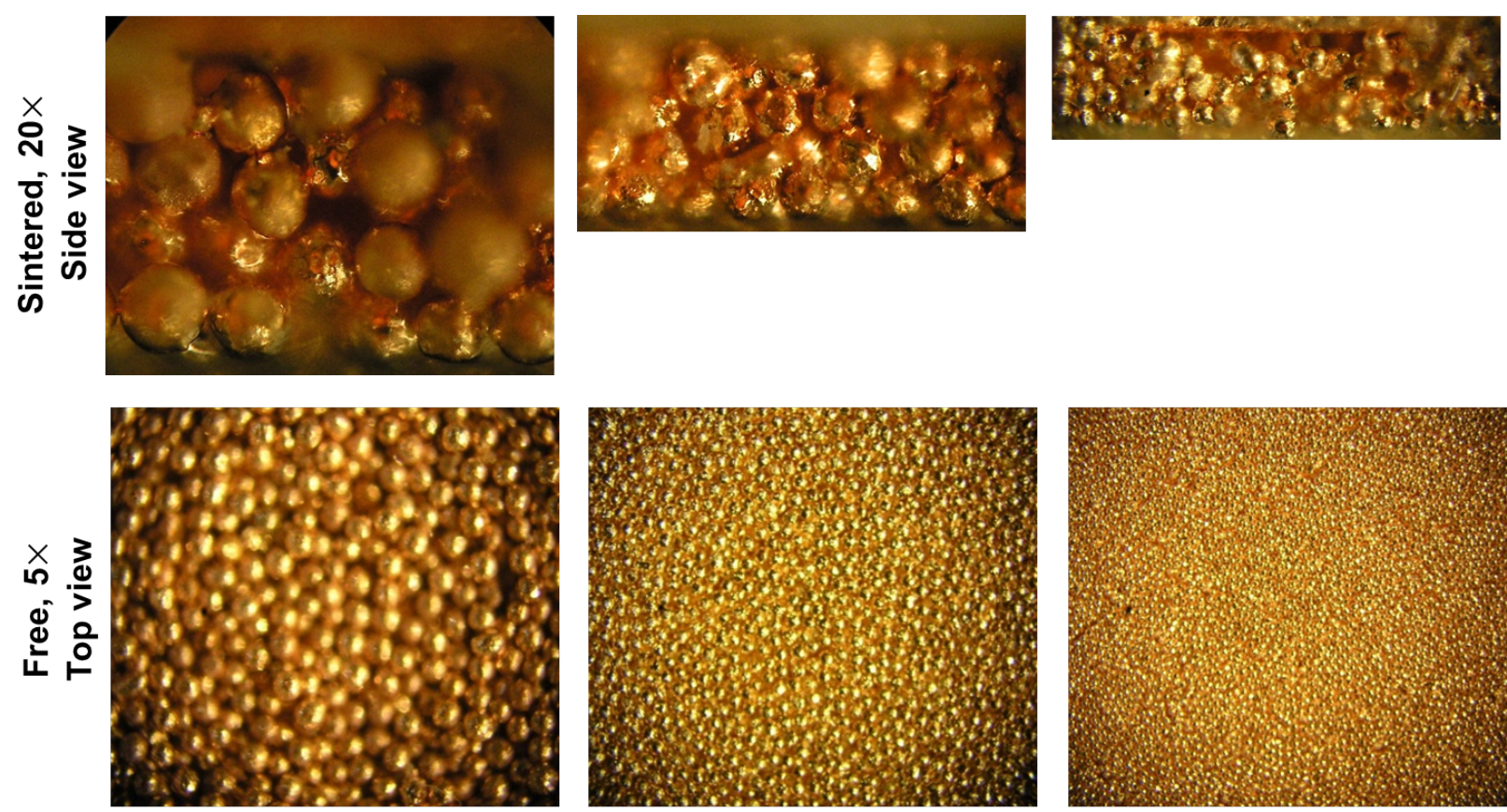

$180-212 \mu \mathrm{m}$

90-106 $\mu \mathrm{m}$

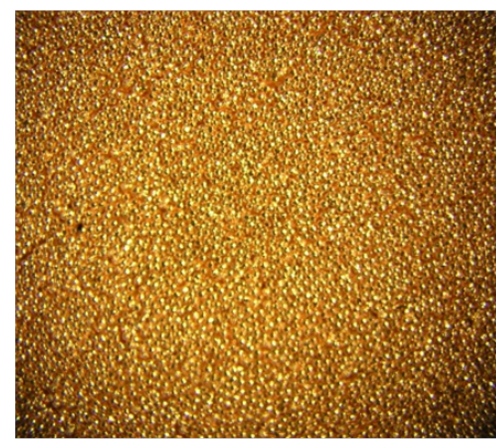

45-53 $\mu \mathrm{m}$

Figure 3. Side view of the sintered coatings at $20 \times$ magnification (top row), and top view of the free particle layer at $5 \times$ magnification (bottom row), for various particles sizes from $45 \mu \mathrm{m}$ to $212 \mu \mathrm{m}$. 


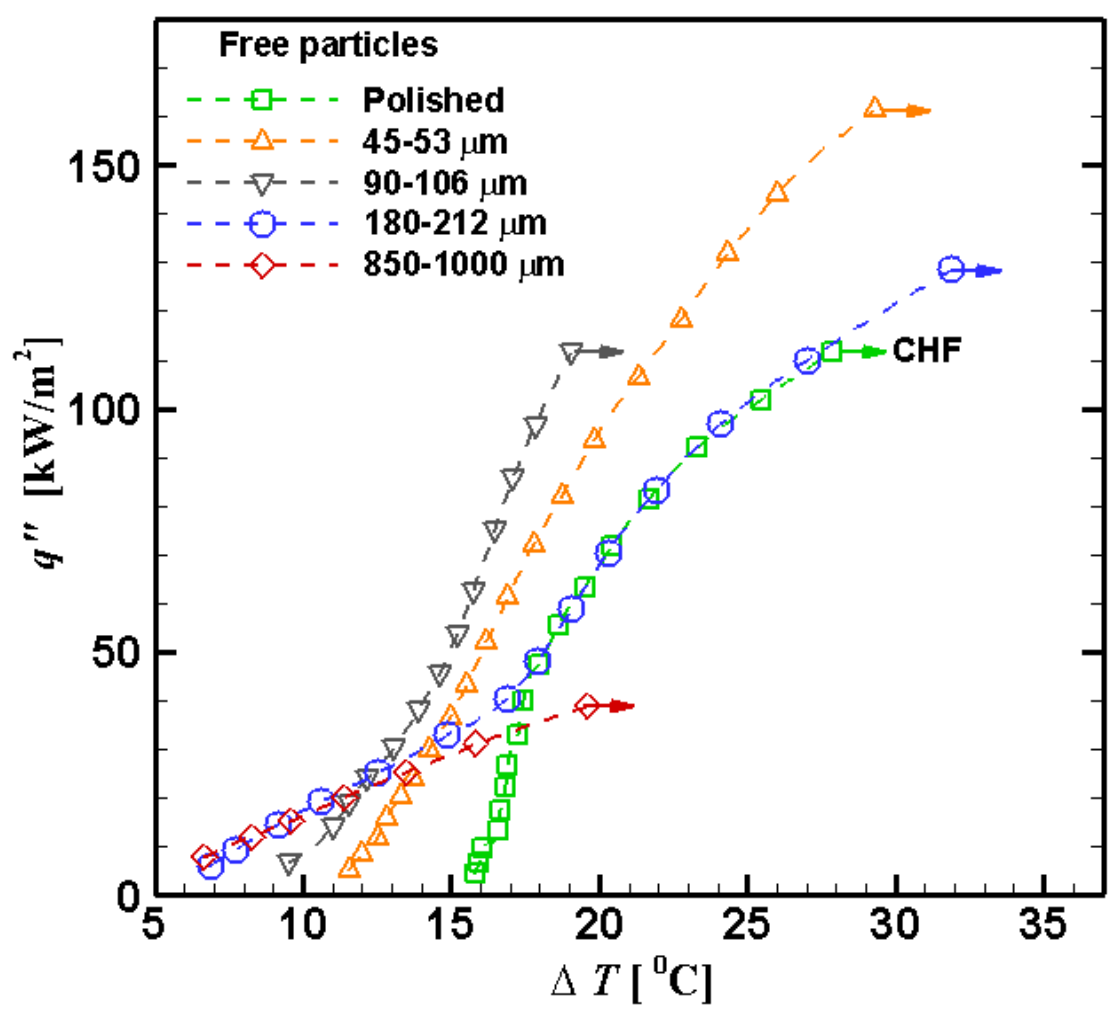

Figure 4. Boiling curves of area-averaged heat flux $\left(q^{\prime \prime}\right)$ versus wall superheat $(\Delta T)$ for a polished surface baseline compared against enhancement using free spherical copper particles $45 \mu \mathrm{m}$ to $1000 \mu \mathrm{m}$ in diameter $(\delta / d=4.8$; porosity $=40-45 \%)$. Critical heat flux is indicated with a horizontal arrow. 


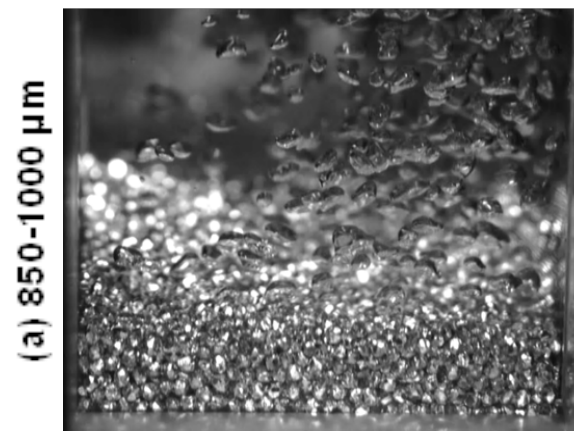

$7.9 \mathrm{~kW} / \mathrm{m}^{2}$

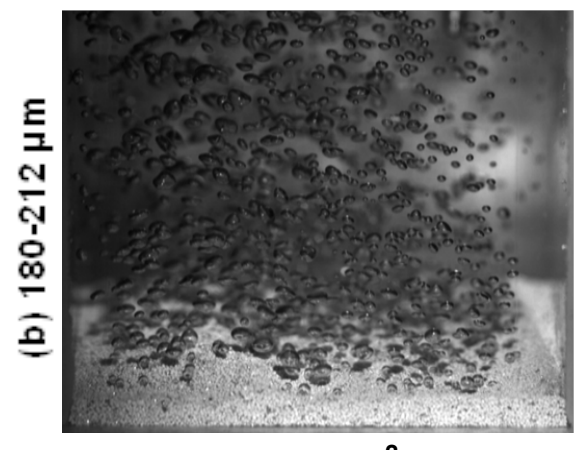

$6.1 \mathrm{~kW} / \mathrm{m}^{2}$

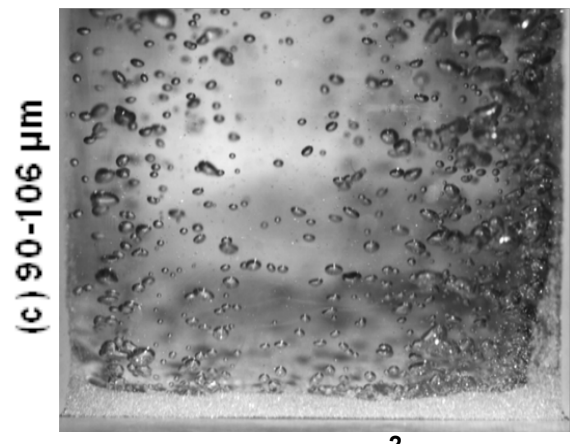

$6.7 \mathrm{~kW} / \mathrm{m}^{2}$

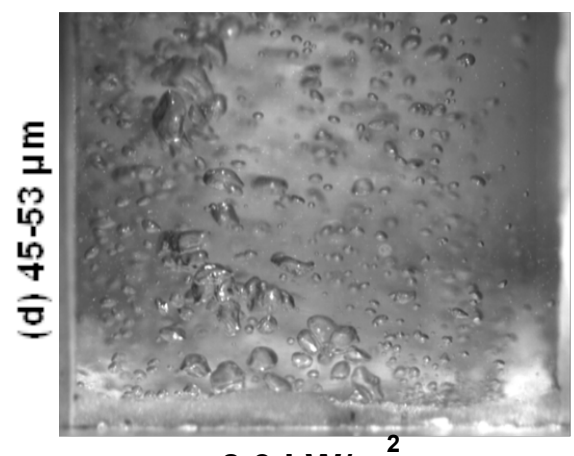

$8.9 \mathrm{~kW} / \mathrm{m}$

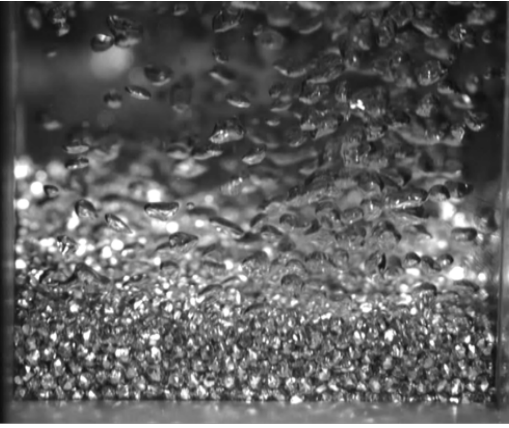

$15.2 \mathrm{~kW} / \mathrm{m}^{2}$

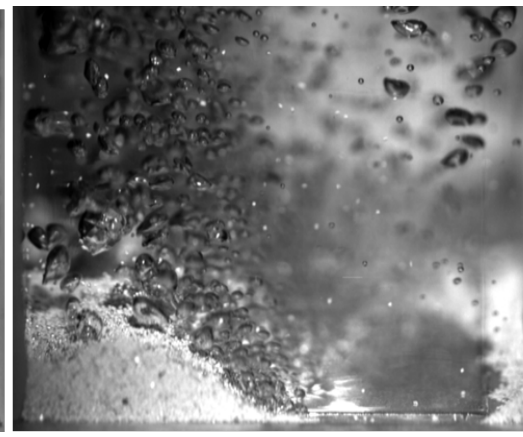

$14.6 \mathrm{~kW} / \mathrm{m}^{2}$

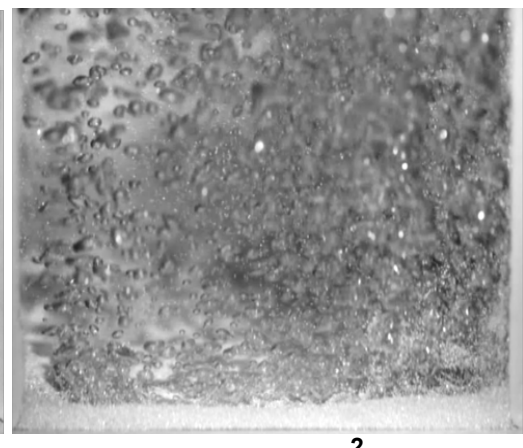

$14.2 \mathrm{~kW} / \mathrm{m}^{2}$

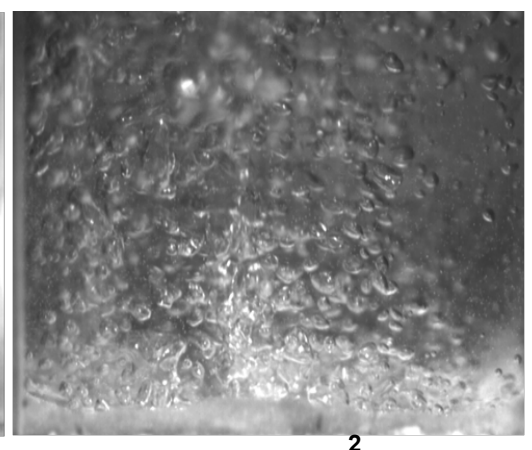

$15.9 \mathrm{~kW} / \mathrm{m}$

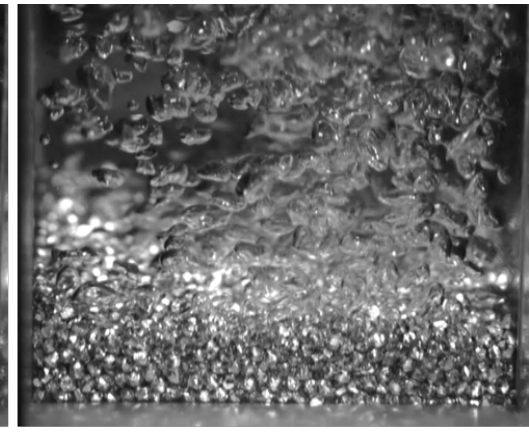

$30.9 \mathrm{~kW} / \mathrm{m}^{2}$

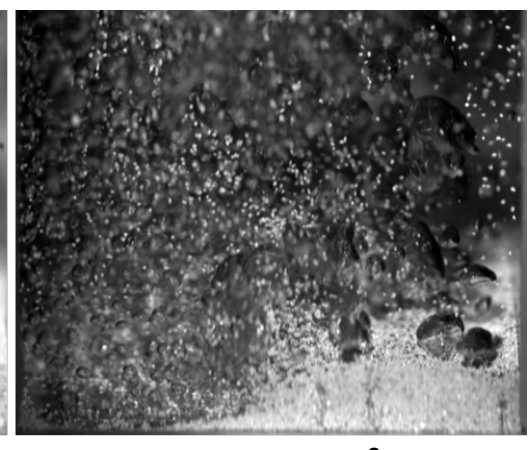

$40.4 \mathrm{~kW} / \mathrm{m}^{2}$

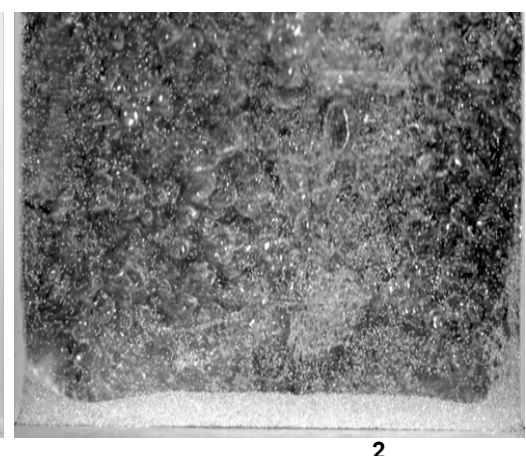

$30.2 \mathrm{~kW} / \mathrm{m}^{2}$

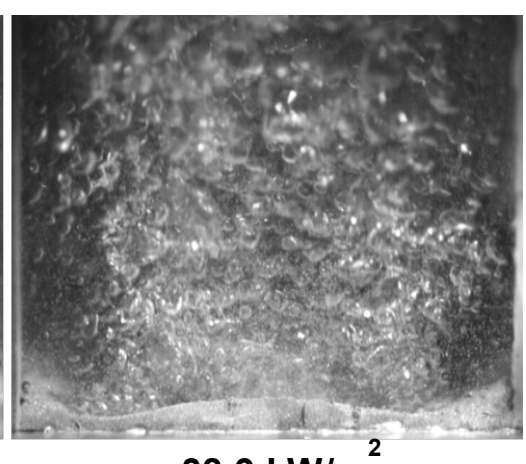

$38.9 \mathrm{~kW} / \mathrm{m}$

Figure 5. Images taken from high-speed visualization at $2000 \mathrm{fps}$ for (a) $850-1000 \mu \mathrm{m}$, (b) $180-212 \mu \mathrm{m}$, (c) $90-106 \mu \mathrm{m}$, and (d) $45-53 \mu \mathrm{m}$ free particle diameters at similar heat fluxes throughout the boiling curve (see Supplementary Video Data). 


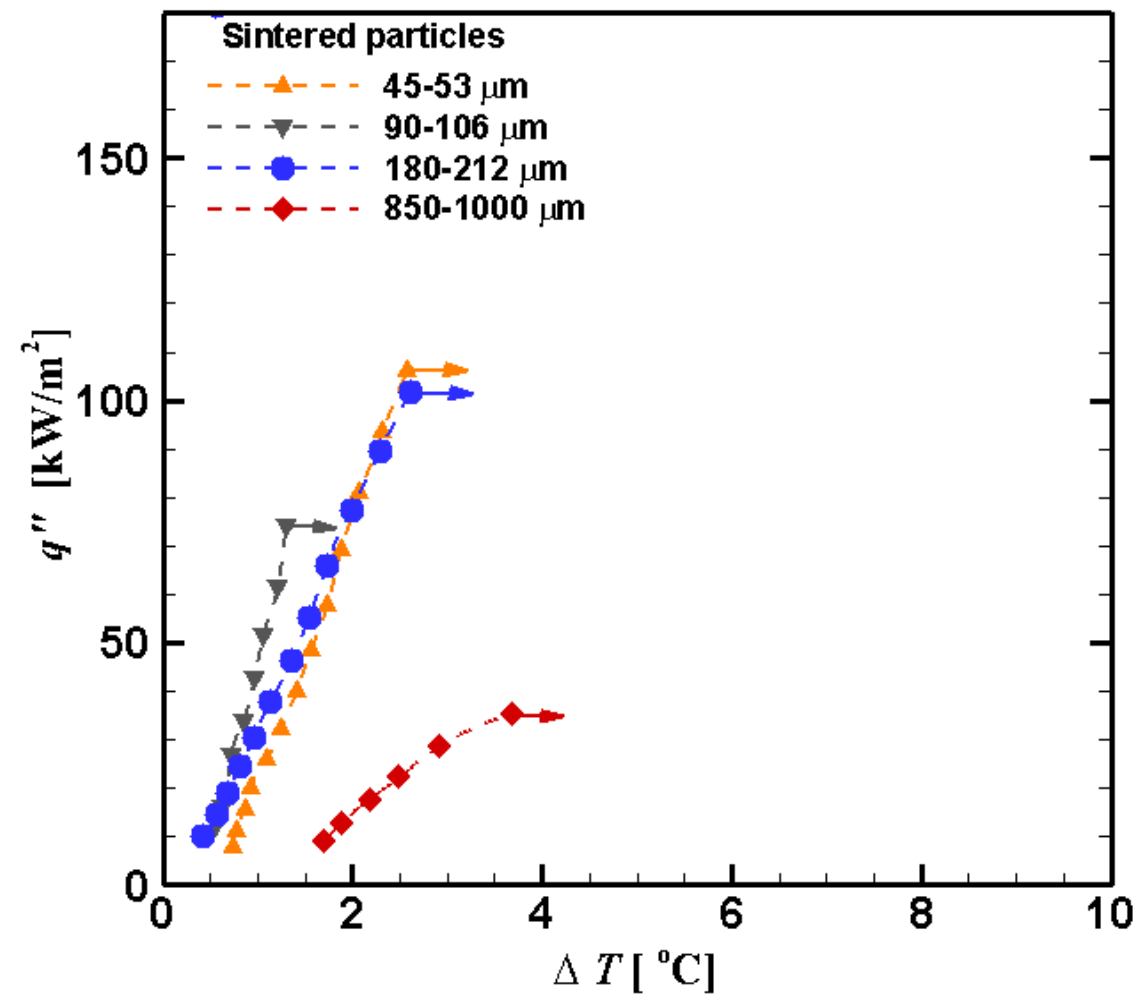

Figure 6. Boiling curves of area-averaged heat flux $\left(q^{\prime \prime}\right)$ versus wall superheat $(\Delta T)$ for surfaces with sintered spherical copper particles $45 \mu \mathrm{m}$ to $1000 \mu \mathrm{m}$ in diameter $(\delta / d \approx 4$ after sintering; porosity $=28$ $40 \%$ ). Critical heat flux is indicated with a horizontal arrow. 


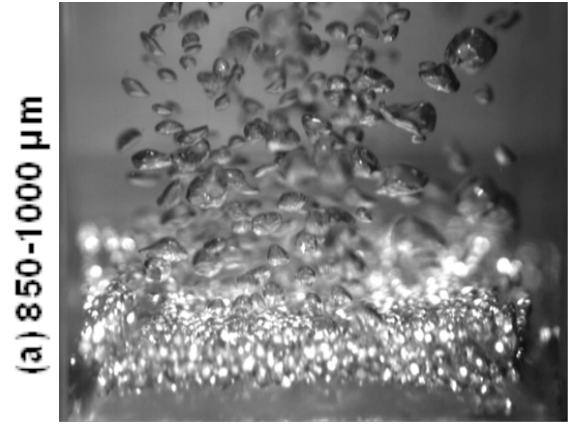

$9.0 \mathrm{~kW} / \mathrm{m}^{2}$

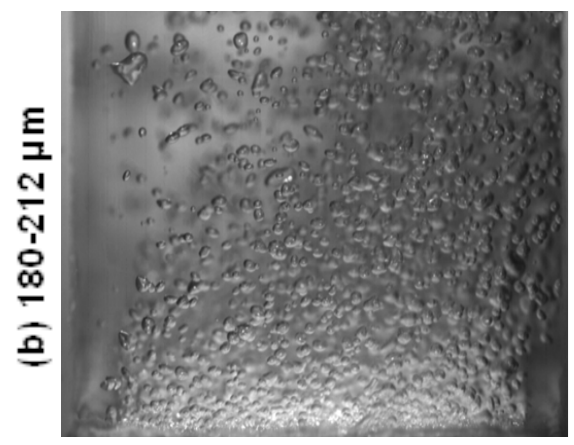

$7.2 \mathrm{~kW} / \mathrm{m}^{2}$

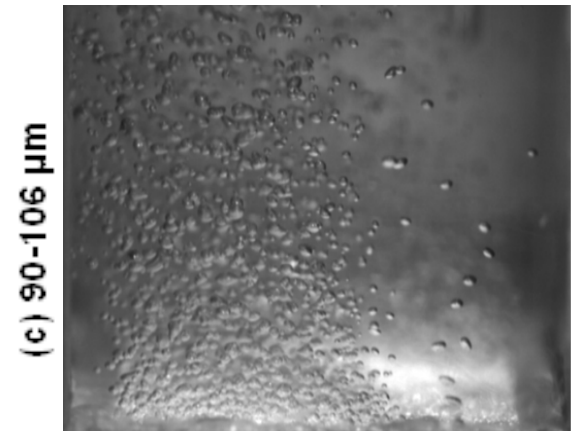

$7.8 \mathrm{~kW} / \mathrm{m}^{2}$

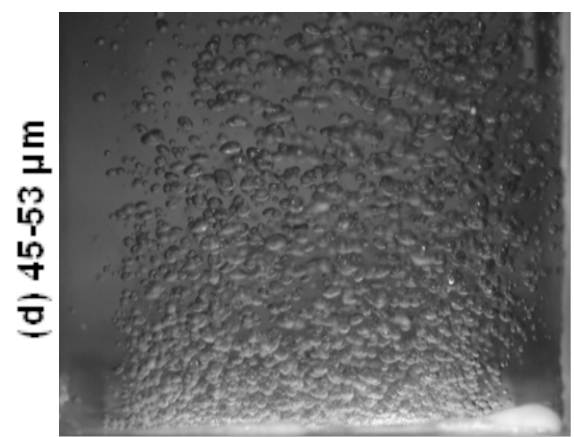

$8.0 \mathrm{~kW} / \mathrm{m}^{2}$

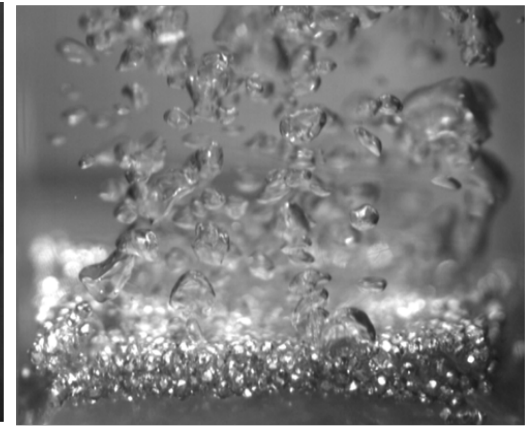

$17.5 \mathrm{~kW} / \mathrm{m}^{2}$

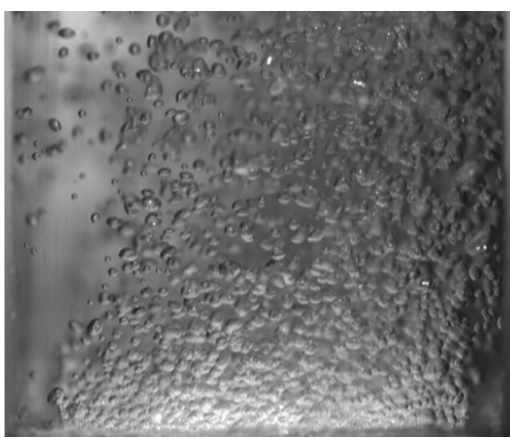

$14.6 \mathrm{~kW} / \mathrm{m}^{2}$

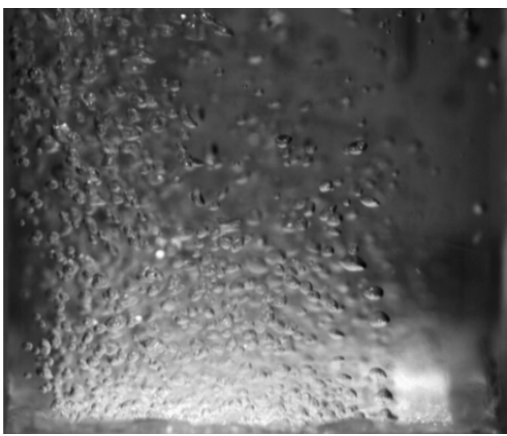

$16.1 \mathrm{~kW} / \mathrm{m}^{2}$

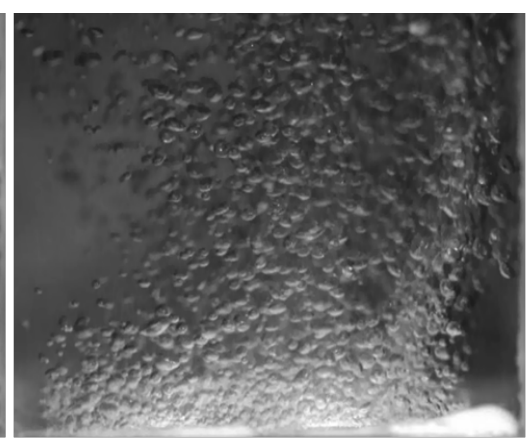

$15.7 \mathrm{~kW} / \mathrm{m}^{2}$

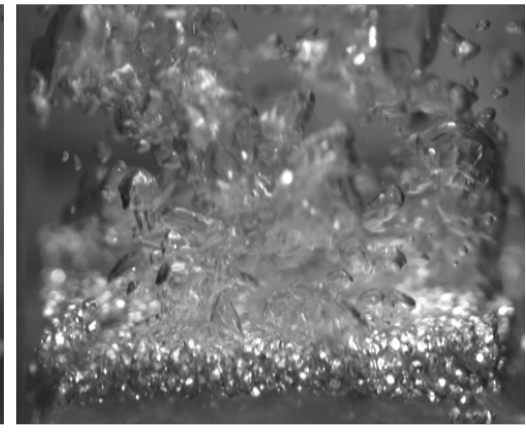

$43.0 \mathrm{~kW} / \mathrm{m}$

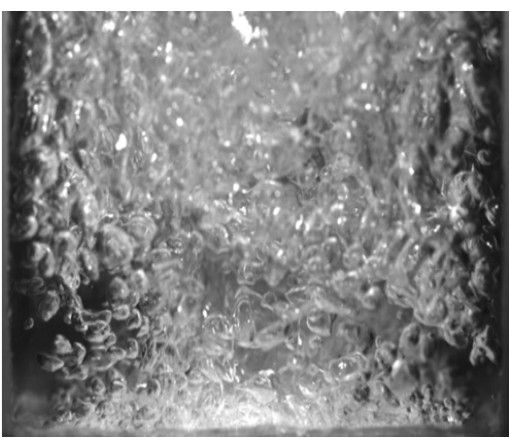

$101.6 \mathrm{~kW} / \mathrm{m}^{2}$

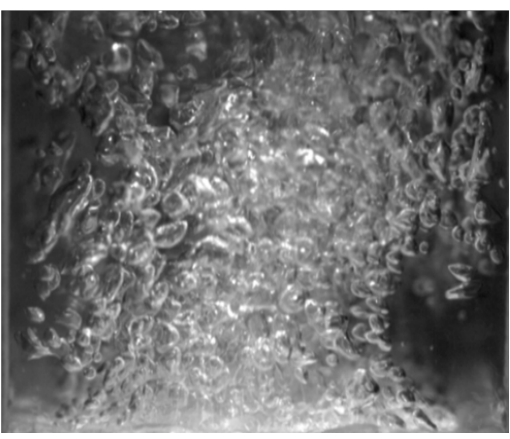

$73.9 \mathrm{~kW} / \mathrm{m}^{2}$

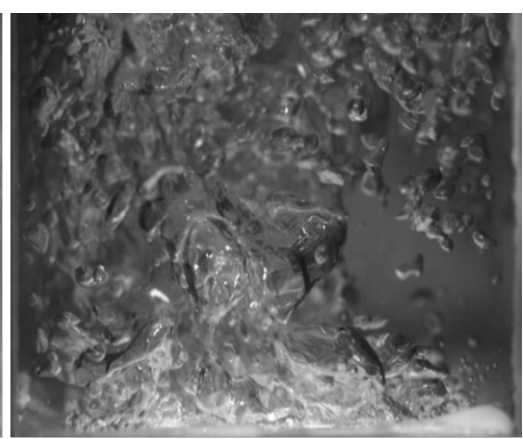

$106.2 \mathrm{~kW} / \mathrm{m}^{2}$

Figure 7. Images taken from high-speed visualization at 2000 fps for (a) $850-1000 \mu \mathrm{m}$, (b) $180-212 \mu \mathrm{m}$, (c) $90-106 \mu \mathrm{m}$, and (d) $45-53 \mu \mathrm{m}$ sintered particle diameters at similar heat fluxes throughout the boiling curve (see Supplementary Video Data). 


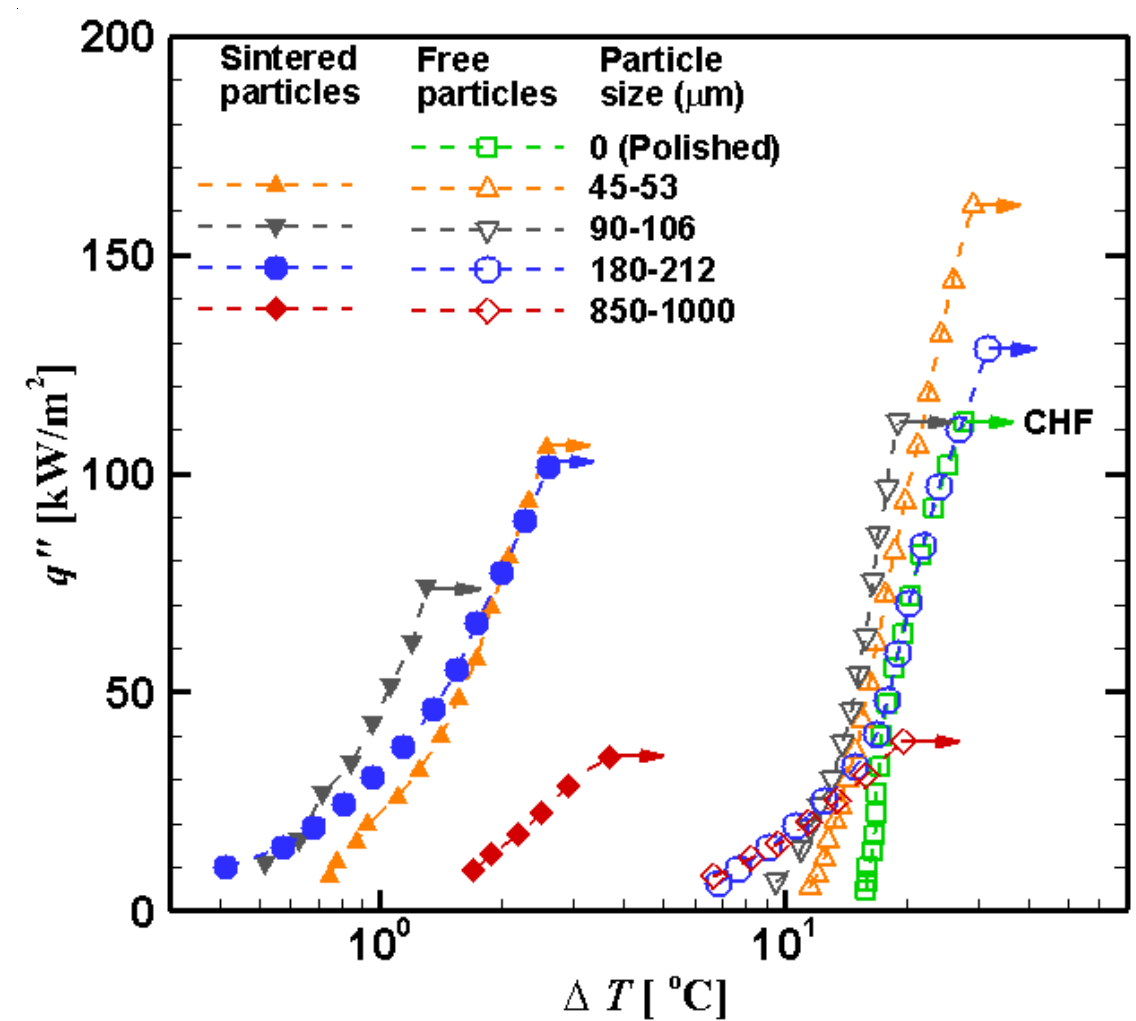

Figure 8. Comparison of trends in boiling curves of area-averaged heat flux $\left(q^{\prime \prime}\right)$ versus wall superheat $(\Delta T)$ for free and sintered particles with diameters ranging from $45 \mu \mathrm{m}$ to $1000 \mu \mathrm{m}$. 